\title{
Fibrous nano composite reinforced surface on WC-Co cemented carbide achieved by pulsed electron beam irradiation and subsequent tempering
}

\author{
Wenhai Peng ${ }^{1, *}$, Shengzhi Hao ${ }^{1,2}$, and Limin Zhao ${ }^{3}$ \\ ${ }^{1}$ Key Laboratory of Materials Modification by Laser, Ion and Electron Beams, Ministry of Education, \\ Dalian University of Technology, Dalian 116024, China \\ ${ }^{2}$ School of Material Science and Engineering, Dalian University of Technology, Dalian 116024, China \\ ${ }^{3}$ School of Material Science and Engineering, Dalian Jiaotong University, Dalian 116021, China
}

Keywords: surface modification, cemented carbide, microstructure evolution, high current pulsed electron beam (HCPEB), tempering, solid state phase transformation.

\begin{abstract}
Exotic microstructures can be tailored by extreme conditions with combined material processing techniques for desirable properties. In this work, an innovative 2-staged process was explored for WC-10Co cemented carbide surface modification. Firstly, rapid thermal cycles were induced by high current pulsed electron beam (HCPEB) irradiation at energy density of $6 \mathrm{~J} / \mathrm{cm}^{2}$, during which the micro-WC/Co was melted and re-solidified into a nano-scaled equiaxed grain microstructure with metastable fcc- $-\mathrm{WC}_{1-\mathrm{x}}$ as the majority phase in the surface layer $(\sim 2 \mu \mathrm{m})$. Thereafter, a subsequent tempering process was applied to the HCPEB-irradiated cemented carbide specimens and the nano equiaxed grains in the surface layer were gradually transferred into nano-scaled fibrous microstructure. Phase transformation was investigated using thermo-gravimetric analysis differential scanning calorimetry (TGA-DSC), confocal laser scanning microscopy (CLSM), scanning electron microscopy (SEM) and X-ray diffractometry (XRD). Analysis showed that the fibrous nano structure resulted from the decomposition of $\mathrm{WC}_{1-\mathrm{x}}$ at $600-700{ }^{\circ} \mathrm{C}$ via fcc- $\mathrm{WC}_{1-\mathrm{x}} \rightarrow$ hex-WC + hcp- $\mathrm{W}_{2} \mathrm{C}$. After the 2-staged process, the surface microhardness was greatly improved.
\end{abstract}

\section{Introduction}

Cemented tungsten carbide holds excellent mechanical properties such as high hardness, fracture strength and wear resistance, thus, has been widely used as drilling, cutting, machining tools[1,2]. To extend applications as a tool material and service span for

*Corresponding author: 1225330232@qq.com 
high-speed/precision machining, further improvement of mechanical properties by surface optimization is highly demanded and favorable for cemented carbide [3]. To date, two main approaches of technical measures were utilized to optimize the surface condition of the WC-based cemented carbide surface[1,4,5]. One is to fabricate nanostructured cemented carbide bulks by improving the sintering process. The other is to fabricate a protective layer on the surface.

In recent years, high current pulsed electron beam (HCPEB), among other energetic beams, has been fast developed as a unique surface modification technology[6-9]. HCPEB irradiation can generate an extreme thermal field (large heating rate $\sim 10^{8-10} \mathrm{~K} / \mathrm{s}$ and large cooling rate $\sim 10^{8-9} \mathrm{~K} / \mathrm{s}$ ) in the surface area of the target material, where a tailored surface layer $(\sim \mu \mathrm{m})$ composed of nano-grained microstructure can be achieved[10-14]. Considering the metastability of the HCPEB-induced microstructure, it is possible that with proper post-HCPEB thermal treatment, this modified surface would undergo a series of solid state phase transformations, resulting in the formation of a surface layer at more stable state with further enhanced property. In this study, WC-10Co cemented carbide was subjected to a 2-stage process, i.e., HCPEB irradiation and the subsequent tempering treatment. A nano fibrous composite was formed on the surface of the cemented carbide after the 2-stage process. Microstructure evolution was analyzed to elucidate the mechanism of the solid-state phase transformation leading to the formation of the fibrous composite surface.

\section{Materials and methods}

Cemented carbide WC-10Co bars were machined by wire cut electrical discharge cutting) into cylinders $(\Phi 15 \mathrm{~mm} \times 8 \mathrm{~mm})$ as specimens. The composition of the cemented carbide is 10 wt. \% Co and WC rest. The typical microstructure of the cemented carbide and the corresponding XRD spectrum are shown in Fig. 1. Angular shaped WC grains with an average grain size of $\sim 1.2 \mu \mathrm{m}$ are bonded by the Co phase. Prior to treatment, one basal plane for each specimen was mechanically ground by diamond disks up to $1200 \#$, and then ultrasonically cleaned in acetone.
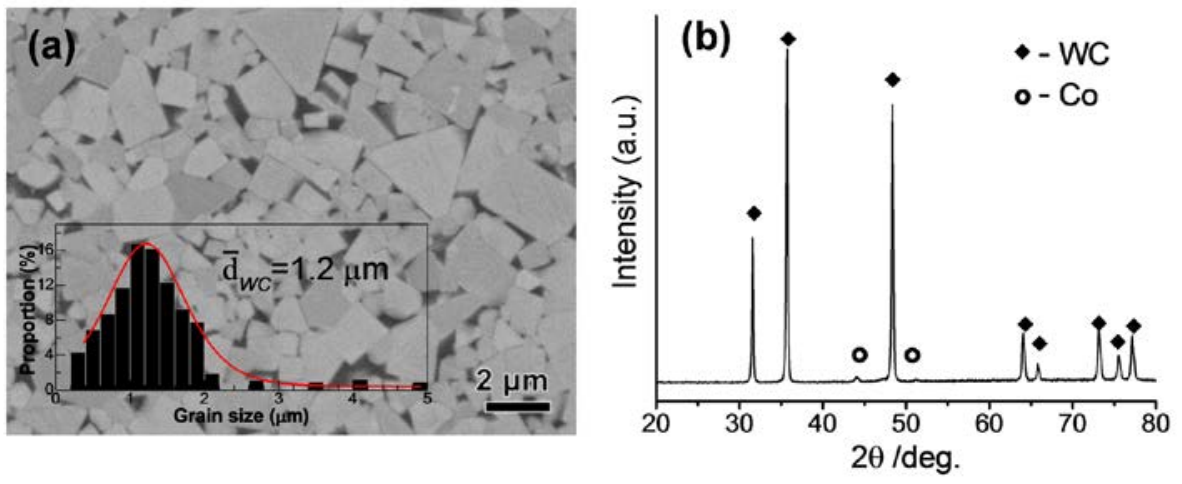

Fig. 1. SEM image(a) and XRD(b) of WC-10Co cemented carbide.

The 2-stage treatment process was illustrated in Fig. 2. A HOPE-I type pulsed electron beam apparatus [6] was used for the irradiation; working parameters in this work are listed as Table 1 . The specimens were firstly irradiated with pulse number $\mathrm{N}=1,6$ and 20 . The phase composition of the WC-10Co cemented carbide changed greatly after HCPEB irradiation (Fig. 3). When $\mathrm{N}=6$ and 20, the $\mathrm{WC}_{1-\mathrm{x}}$ phase became predominant in the surface layer, where some minority phases such as $\mathrm{W}_{2} \mathrm{C}$, graphite were also identified. 

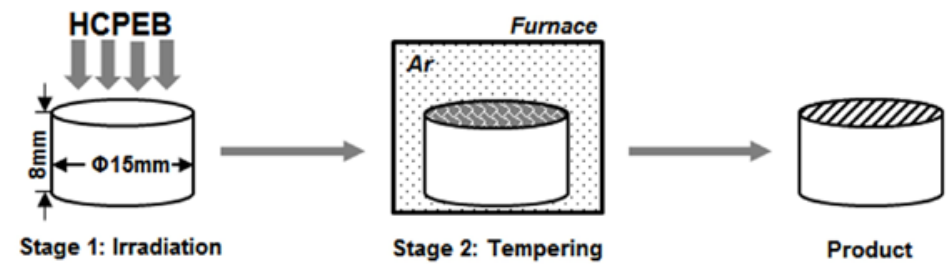

Product

Fig. 2. Schematic illustration of the 2-stage process.

Table 1. Working parameters of the HCPEB irradiation used in the present work.

\begin{tabular}{llllll}
\hline $\begin{array}{l}\text { Accelerating } \\
\text { voltage }(\mathbf{k V})\end{array}$ & $\begin{array}{l}\text { Pulse } \\
\text { duration } \\
(\boldsymbol{\mu} \mathbf{s})\end{array}$ & $\begin{array}{l}\text { Pulse } \\
\text { interval } \\
(\mathbf{s})\end{array}$ & $\begin{array}{l}\text { Energy } \\
\text { density } \\
\left(\mathbf{J} / \mathbf{c m}^{2}\right)\end{array}$ & $\begin{array}{l}\text { Vacuum } \\
\left(\mathbf{1 0}^{-3} \mathbf{P a}\right)\end{array}$ & $\begin{array}{l}\text { Specimen-anode } \\
\text { distance }(\mathbf{c m})\end{array}$ \\
\hline $\mathbf{2 7}$ & 2.5 & 30 & 6 & 6.5 & 10 \\
\hline
\end{tabular}

The exothermal feature in TGA/DSC analysis indicated the favorable temperature range for phase transformation to be about 600 to $1200^{\circ} \mathrm{C}$ (Fig. 4). After primary evaluation, 6 and 20 pulses irradiated specimens were selected for tempering treatment. A GSL-1500X-OTF vacuum tube furnace (heating rate $10{ }^{\circ} \mathrm{C} / \mathrm{min}$ designated) was used for the tempering process of the HCPEB-irradiated specimens with Ar protection. Tempering temperature (TT) was chosen as 500, 600 and $700{ }^{\circ} \mathrm{C}$. The furnace temperature was held constant for $1 \mathrm{~h}$ after thermal ramping, and then cooled down to room temperature within the furnace.

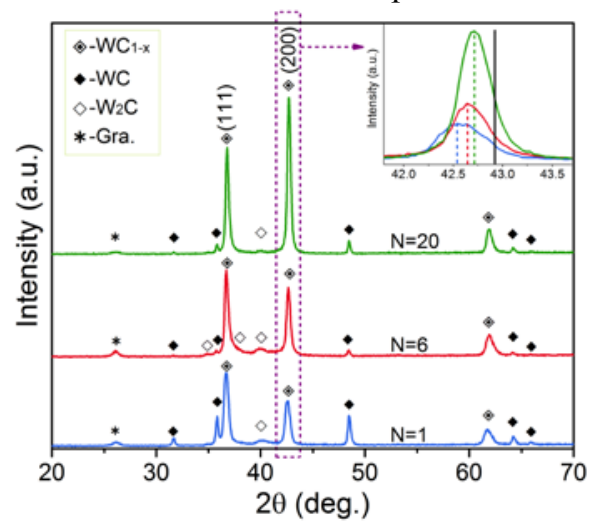

Fig. 3. XRD of WC-10Co cemented carbide irradiated with 1, 6 and 20 pulses of HCPEB.
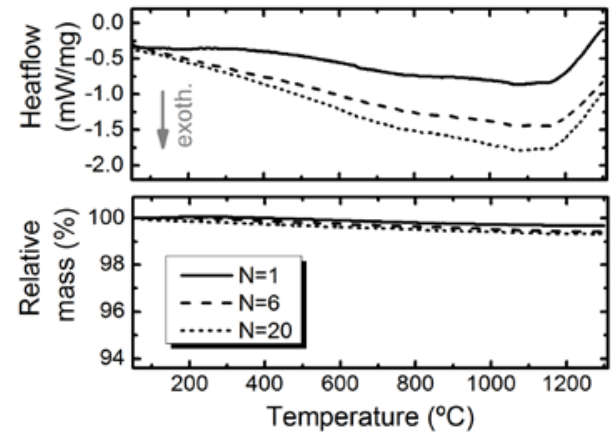

Fig. 4. DSC/TGA signals of WC-10Co cemented carbide irradiated with 1,6 and 20 pulses. 
The phase identification was carried out in an X-ray diffractometer (Shimadzu XRD-6000) with $\mathrm{Cu}-\mathrm{K} \alpha$ radiation. Thermo-gravimetric analysis differential scanning calorimetry (TGA-DSC) was carried out for using a simultaneous thermal analyzer (METTLER TOLEDO TGA/DSC 3+), under Ar gas flow with a heating rate of $10{ }^{\circ} \mathrm{C} / \mathrm{min}$. The microstructure of the specimens was analyzed using a field emission scanning electron microscope (Zeiss Supra55 SEM). Surface microhardness was measured with a Vickers indentation tester (Huayin HV-1000A) at a load of $25 \mathrm{~g}$.

\section{Results and discussion}

Fig. 5 shows the modified microstructure of the specimens treated at different stages. The HCPEB irradiation induced drastic microstructure changes. When $\mathrm{N}=6$, a remelted layer $(\sim 2$ $\mu \mathrm{m}$ ) formed, composed of nano-grained (30-100 nm) microstructure (mainly $\mathrm{WC}_{1-\mathrm{x}}$ phase) with black particles (graphite). When $\mathrm{N}=20$, the nano grained microstructure became more refined and homogeneous $(30-50 \mathrm{~nm})$, graphite particles disappeared. Tempering at $500{ }^{\circ} \mathrm{C}$ affected little on HCPEB-induced surface microstructure. After tempered at $600{ }^{\circ} \mathrm{C}$, a swelling aspect showed on the $\mathrm{N}=6$ surface in parts. After tempered at $700{ }^{\circ} \mathrm{C}$, fibrous microstructure formed $(\sim 20 \times 100 \mathrm{~nm})$. Microstructure change for the $\mathrm{N}=20$ surface resembled feature on the $\mathrm{N}=6$ surface, but the fibrous microstructure was more coarse $(\sim 40$ $\times 300 \mathrm{~nm}$ ) and organized.
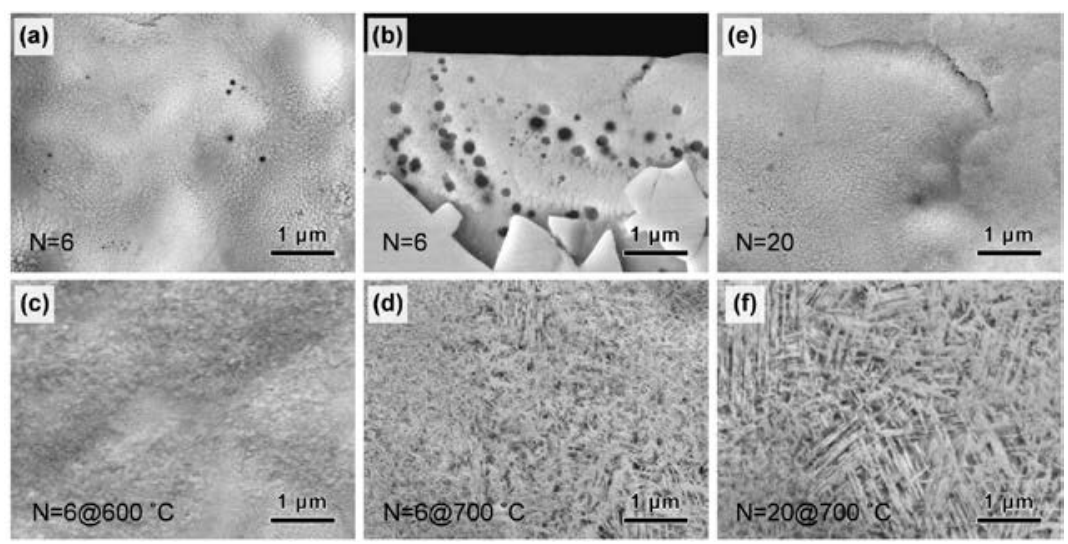

Fig. 5. Typical SEM images of WC-10Co specimen: the surface (a) and cross-sectional view (b) of 6-pulsed, after tempering at $600{ }^{\circ} \mathrm{C}$ (c) and $700{ }^{\circ} \mathrm{C}(\mathrm{d})$; the surface of 20 -pulsed (e) and after tempering at $700{ }^{\circ} \mathrm{C}(\mathrm{f})$.

Fig. 6 shows the XRD spectrums of the post-tempering specimens. Phase transformations were similar for $\mathrm{N}=6$ and $\mathrm{N}=20$ specimens. Obvious changes appeared when TT was elevated to $600{ }^{\circ} \mathrm{C}$, as the peak intensity of the fcc- $\mathrm{WC}_{1-\mathrm{x}}$ phase decreased while that of the hex-WC and hcp- $\mathrm{W}_{2} \mathrm{C}$ phases increased. The $\mathrm{WC}_{1-\mathrm{x}}$ phase faded away after tempered at 700 ${ }^{\circ} \mathrm{C}$. Several points should be highlighted: (1) un-indexed peak pairs (noted with black arrows) on the spectrums of the specimens tempered at 600 and $700{ }^{\circ} \mathrm{C}$ should be corresponded to two transitional phases (TPs) which are considered beneficial for reducing the resistance of solid-state phase transformation. (2) When tempering temperature was elevated from $500{ }^{\circ} \mathrm{C}$ to $600{ }^{\circ} \mathrm{C}$, the peaks of the $\mathrm{WC}_{1-\mathrm{x}}$, such as (111) and (200), shifted slightly to higher angles, which is related to the lattice distortion. 

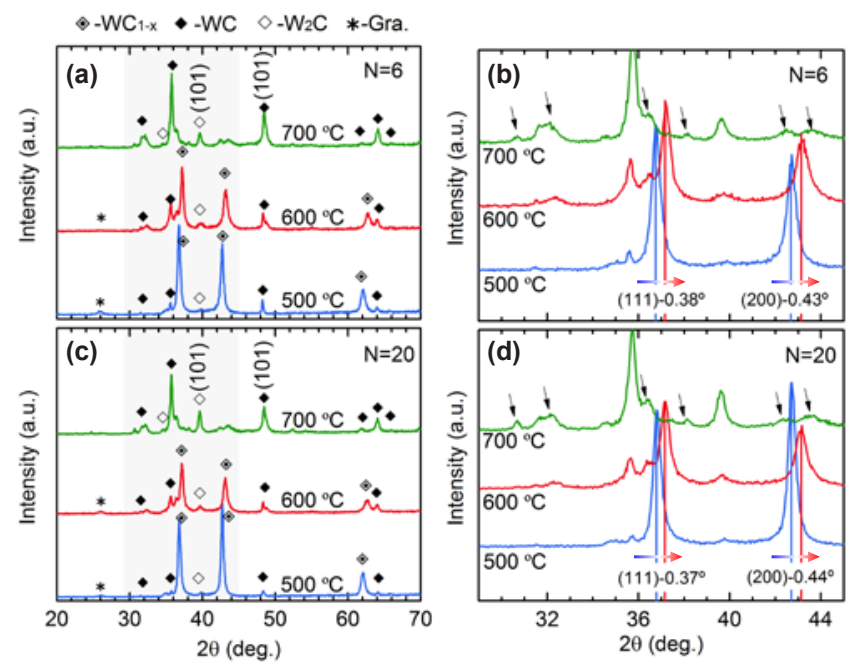

Fig. 6. XRD patterns of HCPEB-irradiated WC-10Co cemented carbide after tempering treatment: (a) 6 pulse irradiated, (c) 20 pulse irradiated; (b) and (d) the corresponding local enlargements.

Surface microhardness of the WC-10Co cemented carbide before and after treatment at different stages is given in Fig. 7. Improvement of microhardness was shown for all treated WC-10Co cemented carbide specimens. For the irradiated WC-10Co cemented carbide specimen, the $\mathrm{N}=20$ surface $(25.9 \mathrm{GPa})$ was much harder than the $\mathrm{N}=6(20.5 \mathrm{GPa})$. After tempering treatment at $500{ }^{\circ} \mathrm{C}$, the $\mathrm{N}=6$ surface was hardened while the $\mathrm{N}=20$ surface softened, indicating that the tempering treatment neutralized the advantage in the $\mathrm{N}=20$ surface. Further elevating the tempering temperature, microhardness increased and reached maximum values at $700{ }^{\circ} \mathrm{C}$ for both $\mathrm{N}=6$ and $\mathrm{N}=20$ (24.8 and $24.0 \mathrm{GPa}$, respectively).

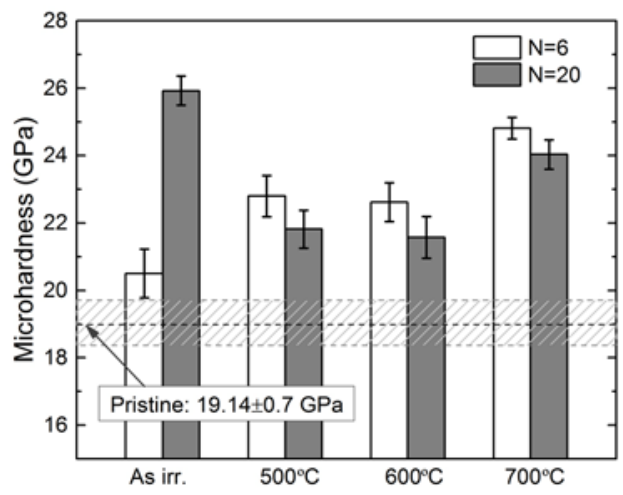

Fig. 7. Microhardness of WC-10Co cemented carbide before and after tempering.

Two main factors contribute to the surface microhardness change of the WC-10Co cemented carbide at different stage processes: i) the grain refinement strengthening which is also seen in other HCPEB irradiated metals and alloys [6-9], ii) the formation of the nano-scaled fibrous composite structure aroused by the subsequent tempering treatment (at $700{ }^{\circ} \mathrm{C}$ ). As for specimens tempered at $500{ }^{\circ} \mathrm{C}$, the process can be considered as annealing since no phase transformation occurred. An annealing hardening was observed for the $\mathrm{N}=6$ surface; similar cases were seen in other nano crystalline materials [15]. However, after same tempering treatment, the $\mathrm{N}=20$ surface was softened. Considering the grain size difference in as irradiated states, the existence of grain size threshold for annealing hardening is indicated. 


\section{Summary}

The main results can be generalized as follows:

(1) HCPEB irradiation with energy density at $6 \mathrm{~J} / \mathrm{cm}^{2}$ induced rapid melting-solidification cycles in the surface layer $(\sim 2 \mu \mathrm{m})$ of WC-Co cemented carbide, leading to the formation of nano-scaled equiaxed grained microstructure, where the metastable $\mathrm{WC}_{1-\mathrm{x}}$ was identified as the majority phase.

(2) The subsequent tempering activated decomposition of the HCPEB-induced nano- $\mathrm{WC}_{1-\mathrm{x}}$, resulting in the formation of the nano fibrous composite (mainly $\mathrm{WC}$ and $\mathrm{W}_{2} \mathrm{C}$ phases) in the surface layer. The grain size on $\mathrm{N}=20$ surface was larger than that on the $\mathrm{N}=6$ surface. The formation of WC phase appeared favorable during the solid-state phase transformation.

(3) The treated specimens exhibited higher microhardness. The improvement of surface hardness was mainly ascribed to grain refinement strengthening, the formation of the nano fibrous phases.

This work was supported by Natural Science Foundation of China (Grant No. 11975002, 51471043) and Anshan Science and Technology Project (2014, 2019).

\section{References}

1. J. García, V. Collado Ciprés, A. Blomqvist, B. Kaplan, V.C. Ciprés, A. Blomqvist, B. Kaplan, Cemented carbide microstructures: a review, Int. J. Refract. Met. Hard Mater. 80 (2019) 40-68.

2. X.X. Liu, X. Song, H. Wang, X.X. Liu, F. Tang, H. Lu, Complexions in WC-Co cemented carbides, Acta Mater. 149 (2018) 164-178.

3. T. Kagnaya, C. Boher, L. Lambert, M. Lazard, T. Cutard, Wear mechanisms of WC-Co cutting tools from high-speed tribological tests, Wear. 267 (2009) 890-897.

4. V. V. Uglov, G.E. Remnev, A.K. Kuleshov, M.S. Saltymakov, Modification of hard alloy by the action of high power ion beams, Surf. Coatings Technol. 206 (2011) 781-784.

5. M. Chandran, F. Sammler, E. Uhlmann, R. Akhvlediani, A. Hoffman, Wear performance of diamond coated WC-Co tools with a CrN interlayer, Diam. Relat. Mater. 73 (2017) 47-55.

6. S. Hao, L. Zhao, Y. Zhang, H. Wang, Improving corrosion and wear resistance of FV520B steel by high current pulsed electron beam surface treatment, Nucl. Instruments Methods Phys. Res. Sect. B Beam Interact. with Mater. Atoms. 356-357 (2015) 12-16.

7. M.C. Li, S.Z. Hao, H. Wen, R.F. Huang, Surface composite nanostructures of AZ91 magnesium alloy induced by high current pulsed electron beam treatment, Appl. Surf. Sci. 303 (2014) 350-353.

8. P. Lyu, Y. Chen, Z. Liu, J. Cai, C. Zhang, Y. Jin, Q. Guan, N. Zhao, Surface modification of CrFeCoNiMo high entropy alloy induced by high-current pulsed electron beam, Appl. Surf. Sci. 504 (2020) 144453.

9. H. Wang, S. Hao, Surface nanostructure and improved microhardness of 40CrNiMo7 steel induced by high current pulsed electron beam treatment, Nucl. Instruments Methods Phys. Res. Sect. B Beam Interact. with Mater. Atoms. 403 (2017) 45-50. 
10. J. Lu, S. Hao, L. Zhao, W. Peng, H. Liu, Y. Wu, S. Zhou, Hybrid disorder carbon fiber cathode for high current pulsed electron beam emission, Appl. Surf. Sci. 511 (2020) 145511.

11. B. Gao, L. Hu, S.W. Li, Y. Hao, Y.D. Zhang, G.F. Tu, T. Grosdidier, Study on the nanostructure formation mechanism of hypereutectic Al-17.5Si alloy induced by high current pulsed electron beam, Appl. Surf. Sci. 346 (2015) 147-157.

12. J.W. Murray, J.C. Walker, A.T. Clare, Nanostructures in austenitic steel after EDM and pulsed electron beam irradiation, Surf. Coatings Technol. 259 (2014) 465-472.

13. W. Peng, S. Hao, L. Zhao, J. Chen, W. Li, Formation mechanism of graphite nanospheres in W-C-Co system under high current pulsed electron beam irradiation, Mater. Lett. 244 (2019) 207-210.

14. W. Peng, S. Hao, J. Chen, W. Li, L. Zhao, J. Deng, Surface composite microstructure and improved mechanical property of YG10X cemented carbide induced by high current pulsed electron beam irradiation, Int. J. Refract. Metals Hard Mater. 78 (2019) 233-239.

15. X. Huang, N. Hansen, N. Tsuji, Hardening by Annealing and Nanostructured Metals, Science (80-. ). 312 (2006) 249-252. 